\title{
Differential Transform Technique for Higher Order Boundary Value Problems
}

\author{
Abiodun A. Opanuga ${ }^{1}$, Hilary I. Okagbue ${ }^{1}$, Sunday O. Edeki ${ }^{1} \&$ Olasunmbo O. Agboola ${ }^{1}$ \\ ${ }^{1}$ Department of Mathematics, College of Science \& Technology, Covenant University, Ota, Nigeria \\ Correspondence: Abiodun A. Opanuga, Department of Mathematics, College of Science \& Technology, \\ Covenant University, Ota, Nigeria. Tel: 23480-6984-1259. E-mail: abiodun.opanuga@covenantuniversity.edu.ng
}

Received: May 5, 2015

Accepted: August 25, $2015 \quad$ Online Published: November 30, 2015

doi:10.5539/mas.v9n13p224

URL: http://dx.doi.org/10.5539/mas.v9n13p224

\begin{abstract}
This paper presents the approximate solution of higher order boundary value problems by differential transform method. Two examples are considered to illustrate the efficiency of this method. The results converge rapidly to the exact solution and are shown in tables and graphs.
\end{abstract}

Keywords: differential transform method, boundary value problems, series solution

\section{Introduction}

Recently, studies showed that higher order boundary value problems arise in the areas of fluid dynamics, hydrodynamics and hydromagnetic stability and other applied sciences. Specifically, fifth-order boundary value problems arise in viscoelastic fluid. The problem was considered by Wazwaz (2001) using the decomposition method. Caglar et al (2006) solved it via B-spline interpolation and compared the results with finite element and finite volume methods and Triphathi (2012). Sixth order boundary value problems occur in astrophysics and it has attracted the attention of researchers like Wazwaz (2001) who investigated it using modified decomposition method, He (2003) used variational approach method and Erturk (2007) approached it via differential transformation method. However, seventh order boundary value problems that arise in modeling induction motors with two rotor circuits was considered by Siddiqi et. al (2012) while eight-order boundary value problem which occur in hydrodynamic and hydromagnetic stability was also studied by Siddiqi et al (1996) and Mohammad-Jawad (2010). Other authors who have also studied higher order boundary value problems include Wazwaz (2000), Othman et al. (2010) and Mohyud-Din (2010).

The differential transform method is applied in this work to solve boundary value problems of ninth and twelfth orders. This method was proposed by Zhou (1986). Some authors who have also adopted this method include, Opanuga et al (2014) on systems of ordinary differential equations, also Opanuga et al (2015) applied it in numerical solution of two-point boundary value problems, Edeki et al (2014) analyzed linear and nonlinear differential equations and finally Edeki et al (2015), in transformed Cauchy-Euler equidimensional equations of homogenous type.

\section{Analysis of Differential Transform Method}

Let the arbitrary function $y=v(x)$ be expressed in Taylor series about a point $x=x_{0}$ as

$$
v(x)=\sum_{k=0}^{\infty} \frac{x^{k}}{k !}\left[\frac{d^{k} v}{d x^{k}}\right]_{x=x_{0}}
$$

with the differential transformation of $V(k)$ given as

$$
V(k)=\frac{1}{k !}\left[\frac{d^{k} v}{d x^{k}}\right]_{x=x_{0}}
$$

We then obtain the inverse differential transform of $V(k)$ as 


$$
v(x)=\sum_{k=0}^{\infty} v(k)\left(x-x_{0}\right)^{k}
$$

The following theorems can be obtained from equations (1), (2) and (3)

(i) If $v(x)=v_{1}(x) \pm v_{2}(x)$ then, $V(k)=V_{1}(k) \pm V_{2}(k)$

(ii) If $v(x)=\beta v_{1}(x)$ then, $V(k)=\beta V_{1}(k)$

(iii) If $v(x)=\frac{d^{m} v_{1}(x)}{d x^{m}}$ then, $V(k)=\frac{(k+m) !}{k !} V_{1}(k+m)$

(iv) If $v(x)=v_{1}(x) v_{2}(x)$ then, $V(k)=\sum_{m=0}^{k} V_{2}(m) V_{1}(k-m)$

(v) If $v(x)=x^{a}$ then, $V(k)=\delta(k-a)$ where $\delta(k-a)=\left\{\begin{array}{l}1, \text { if } k=a \\ 0, \text { if } \mathrm{k} \neq \mathrm{a}\end{array}\right.$

(vi) If $v(x)=e^{\beta x}$ then, $V(k)=\frac{\beta^{k}}{k !}$

\section{Numerical Examples}

Example 1: We consider the following ninth order boundary value problem.

$$
u^{9}(t)=-9 e^{t}+u(t), \quad 0<t<1,
$$

and the boundary conditions are

$$
\begin{array}{ll}
u^{(k)}(0)=(1-k), & k=0,1,2,3,4 \\
u^{(k)}(1)=-k e, & k=0,1,2,3 .
\end{array}
$$

The exact solution for the bvp is

$$
u(t)=(1-t) e^{t}
$$

The differential transformation of equation (4) is given as

and differential transformation of the boundary conditions yield

$$
U(n+9)=\frac{n !}{(n+9) !}\left[U(n)-\frac{9}{n !}\right] .
$$

$$
U(0)=1, U(1)=0, U(2)=-\frac{1}{2}, U(3)=-\frac{1}{3}, U(4)=-\frac{1}{8}
$$

With

$$
A=\frac{u^{v}(t)}{5 !}=U(5), B=\frac{u^{v i}(t)}{6 !}=U(6), C=\frac{u^{v i i}(t)}{7 !}=U(7), D=\frac{u^{v i i i}(t)}{8 !}=U_{1}
$$


Using the boundary conditions (8) in the transformed equation (7) at $x=0$, we obtain the solution of $u(t)$, for $t \geq 9$. The constants A, B, C and D can be determined by using the boundary conditions (8) at $x=1$ giving rise to the following systems

$$
\begin{aligned}
& \frac{2849503}{68428800}+\frac{A}{20}+\frac{B}{720}+\frac{C}{5040}+\frac{D}{40320} \\
& 0.218055584+\frac{A}{24}+\frac{B}{120}+\frac{C}{720}+\frac{D}{5040} \\
& 0.934722556+\frac{A}{6}+\frac{B}{24}+\frac{C}{120}+\frac{D}{720} \\
& 3.141670336+\frac{A}{2}+\frac{B}{6}+\frac{C}{24}+\frac{D}{120}
\end{aligned}
$$

We then solve the above system of equations to obtain the following:

$$
A=-3.999989123, B-5.000214682, C=-5.998305826, D=-7.005270192
$$

We finally obtain the following series of equation using the inverse transformation equation (3) up to $T=18$

$$
\begin{aligned}
u(t)= & 1-\frac{1}{2} t^{2}-\frac{1}{3} t^{3}-\frac{1}{8} t^{4}-0.03333324269 t^{5}-0.006944742614 t^{6}- \\
& 0.001190140045 t^{7}-0.0001737418202 t^{8}-\frac{1}{45360} t^{9}-\frac{1}{403200} t^{10}- \\
& \frac{1}{3991680} t^{11}-\frac{1}{43545600} t^{12}-\frac{1}{518918400} t^{13}-1.491195680 \times 10^{-10} t^{14}- \\
& 1.070619340 \times 10^{-11} t^{15}-7.168406272 \times 10^{-13} t^{16}-4.499813299 \times 10^{-14} t^{17}- \\
& \frac{1}{376610217984000} t^{18}
\end{aligned}
$$

Table1. Numerical solution for example1

\begin{tabular}{lllll}
\hline & $\begin{array}{l}\text { EXACT } \\
\mathrm{t}\end{array}$ & DOLUTION & & \\
\hline 0 & 1.0000000 & 1.0000000 & 0 & \\
0.1 & 0.9946538 & 0.9946538 & $6.41 \mathrm{E}-13$ & \\
0.2 & 0.9771222 & 0.9771222 & $1.39 \mathrm{E}-11$ & \\
0.3 & 0.9449012 & 0.9449012 & $6.78 \mathrm{E}-11$ & \\
0.4 & 0.8950948 & 0.8950948 & $1.72 \mathrm{E}-10$ & \\
0.5 & 0.8243606 & 0.8243606 & $2.89 \mathrm{E}-10$ & \\
0.6 & 0.7288475 & 0.7288475 & $3.52 \mathrm{E}-10$ & \\
0.7 & 0.6041258 & 0.6041258 & $3.03 \mathrm{E}-10$ & \\
0.8 & 0.4451082 & 0.4451082 & $1.04 \mathrm{E}-10$ & \\
0.9 & 0.2459603 & 0.2459603 & $4.24 \mathrm{E}-10$ & \\
1 & 0 & $-2.09 \mathrm{E}-09$ & $2.09 \mathrm{E}-09$ & \\
\hline
\end{tabular}




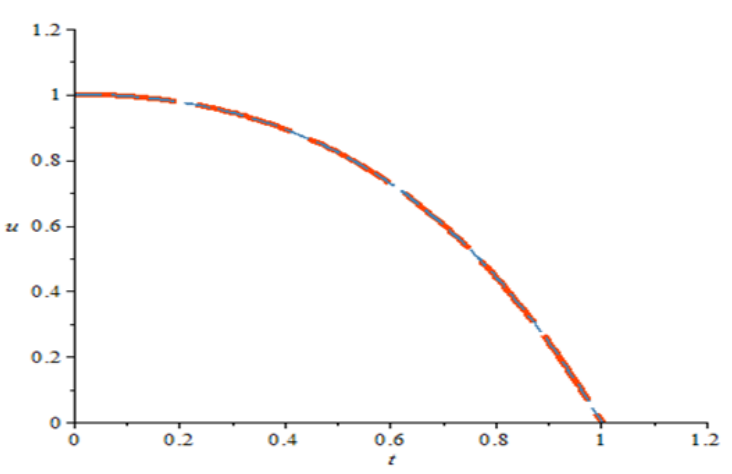

Figure 1. Graph of example 1

EXAMPLE 2: We consider the following twelfth order boundary-value problem

$$
u^{12}(t)=2 e^{t} u^{2}(t)+u^{\prime \prime \prime}(t), \quad 0<t<1
$$

with the following boundary conditions

$$
u^{2 k}(0)=1, u^{2 k}(1)=e^{-1}, \quad k=0,1,2,3,4,5 .
$$

The exact solution for the boundary -value problem is written as

$$
u(t)=e^{-t}
$$

The differential transform of equation (12) is given as

$$
U(n+12)=\frac{n !}{(n+12) !}\left(2 \sum_{r=0}^{n} \sum_{s=0}^{r} \frac{(1)^{s}}{s !} U(r-s)(n-r)+(n+3) ! U(n+3)\right)
$$

and the differential transformation of the boundary conditions yield

$$
\begin{gathered}
Y(0)=1, Y(2)=\frac{1}{2 !}, Y(4)=\frac{1}{4 !}, Y(6)=\frac{1}{6 !}, Y(8)=\frac{1}{8 !}, Y(10)=\frac{1}{10 !} \\
A=\frac{u^{\prime}}{1 !}=U(1), B=\frac{u^{\prime \prime \prime}}{3 !}=U(3), C=\frac{u^{v}}{5 !}=U(5), D=\frac{u^{v i i}}{7 !}=U(7), \\
E=\frac{u^{i x}}{9 !}=U(9), F=\frac{u^{v i i}}{11 !}=U(11)
\end{gathered}
$$

Using the transformed boundary conditions (16) in equation (15) at $x=0$, we obtain the series solution $u(t)$, for $t \geq 12$. The constants A, B, C and D are evaluated by using the boundary conditions (16) at $x=1$ to give the system of equations below. 


$$
\begin{aligned}
& 1.175201197+A+\frac{79833601 B}{479001600}+\frac{C}{120}+\frac{D}{5040}+\frac{E}{362880}+\frac{F}{39916800} \\
& 1.175201468+\frac{3628801 B}{3628800}+\frac{C}{6}+\frac{D}{120}+\frac{E}{5040}+\frac{F}{362880} \\
& 1.175225719+\frac{B}{40320}+C+\frac{D}{6}+\frac{E}{120}+\frac{F}{5040} \\
& 1.176565004+\frac{B}{720}+D+\frac{E}{6}+\frac{F}{120} \\
& 1.215453893+\frac{B}{24}+E+\frac{F}{6} \\
& 1.63212056+\frac{B}{2}+H
\end{aligned}
$$

Solving the system of equations yield the following:

$$
\begin{aligned}
& A=-0.9999983614, B=-1.000016175, C=-0.9998407322, D=-1.00155899, \\
& E=-0.9851011403, F=-1.132112473
\end{aligned}
$$

\begin{tabular}{|c|c|c|c|}
\hline & EXACT & DTM & ABSOLUTE \\
\hline $\mathrm{t}$ & SOLUTION & SOLUTION & ERROR \\
\hline 0 & 1.00000000 & 1.00000000 & 0 \\
\hline 0.1 & 0.90483742 & 0.904837579 & $1.61 \mathrm{E}-07$ \\
\hline 0.2 & 0.81873075 & 0.81873106 & $3.07 \mathrm{E}-07$ \\
\hline 0.3 & 0.74081822 & 0.740818643 & 4.22E-07 \\
\hline 0.4 & 0.67032005 & 0.670320542 & 4.96E-07 \\
\hline 0.5 & 0.60653066 & 0.606531181 & $5.21 \mathrm{E}-07$ \\
\hline 0.6 & 0.54881164 & 0.548812132 & $4.96 \mathrm{E}-07$ \\
\hline 0.7 & 0.4965853 & 0.496585725 & $4.22 \mathrm{E}-07$ \\
\hline 0.8 & 0.44932896 & 0.44932927 & $3.06 \mathrm{E}-07$ \\
\hline 0.9 & 0.40656966 & 0.40656982 & $1.6 \mathrm{E}-07$ \\
\hline 1 & 0.36787944 & 0.36787944 & $1.45 \mathrm{E}-09$ \\
\hline
\end{tabular}

We then obtain the following series solution using the inverse transformation equation (3) up to $T=20$

$$
\begin{aligned}
u(t)= & 1-0.9999983614 t+\frac{1}{2} t^{2}-0.1666693625 t^{3}+\frac{1}{24} t^{4}- \\
& 0.008332006102 t^{5}+\frac{1}{720} t^{6}-0.0001987218847 t^{7}+\frac{1}{40320} t^{8}- \\
& 2.714674659 \times 10^{-6} t^{9}+\frac{1}{3628800} t^{10}-2.836180438 \times 10^{-8} t^{11}+ \\
& 2.087641931 \times 10^{-9} t^{12}-1.605893858 \times 10^{-10} t^{13}+3.65385 \times 10^{-15} t^{14}+ \\
& 3.058816015 \times 10^{-12} t^{15}-1.053272498 \times 10^{-12} t^{16}+3.317537471 \times 10^{-13} t^{17}- \\
& 1.104704058 \times 10^{-13} t^{18}+4.141550914 \times 10^{-14} t^{19}-1.876145228 \times 10^{-14} t^{20}
\end{aligned}
$$

Table 2. Numerical solution for example 


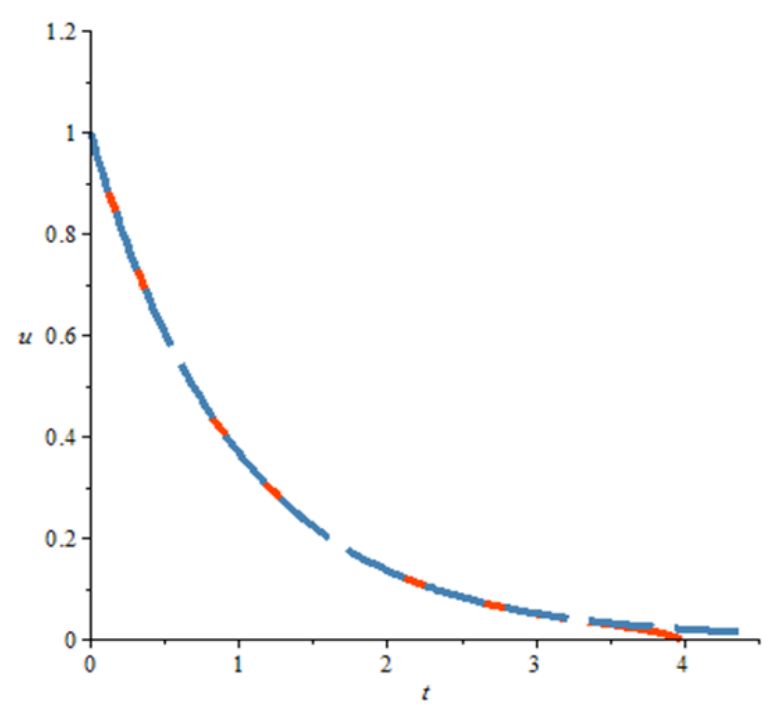

Figure 2. Graph of examlpe 2

\section{Concluding Remarks}

This paper has applied differential transform method to solve ninth-order and twelfth-order boundary value problems. The method is easy to apply, accurate and efficient. This is evident from table 1 and the graphical representations of the solution which show strong agreement with the exact solution.

\section{Acknowledgements.}

The authors are grateful to Covenant University for the financial support and the anonymous reviewers for their constructive comments.

\section{References}

Caglar, H., Caglar, N., \& Elfaituri, K. (2006). B-Spline interpolation compared with finite element and finite volume methods which applied to two-point boundary value problems. Appl. Math. Comput, 175, $72-79$

Edeki, S. O., Opanuga, A. A., Okagbue, H. I., Akinlabi, G. O., Adeosun, S. A., \& Osheku, A. S. (2015). A numerical-computational technique for solving transformed Cauchy-Euler equidimensional equations of homogenous type. Advanced Studies in Theoretical Physics, 9, 85-92. http://dx.doi.org/10.12988/astp.2015.412160

Edeki, S. O., Opanuga, O. O., \& Okagbue, H. I. (2014). On iterative techniques for numerical solutions of linear and nonlinear differential equations. J. Math. Comput. Sci., 4(4), 716 -727.

Ert"urk, V. S. (2007). Application of differential transformation method to linear sixth-order boundary value problems. Applied Mathematical Sciences, 2(1), 51-58.

He, J. H. (2003). Variational approach to the sixth-order boundary value problems. Applied Mathematics and Computation, 143, 537-538.

Mohammad-Jawad, A. J. (2010). Solving linear and non-linear eighth-order boundary value problems by three numerical methods. Eng. \& Tech. Journal, 24, 28.

Mohyud-din T. (2010). Solution of tenth and ninth -order boundary value problems by Modified variational iteration method. Application and Applied Mathematics, 5(1), 11-25.

Opanuga, A. A, Edeki, S. O., Okagbue, H. I., Akinlabi, G. O., Osheku, A. S., \& Ajayi, B. (2014). On numerical solutions of systems of ordinary differential equations by numerical-analytical method. Applied Mathematical Sciences, 8(164), 8199-8207. http://dx.doi.org/10.12988/ams.2014.410807

Opanuga, A. A., Edeki, S. O., Okagbue, H. I., \& Akinlabi, G. O. (2015). Numerical Solution of Two-Point Boundary Value Problems via Differential Transform Method. Global Journal of Pure and Applied Mathematics, 11(2), 801-806. 
Othman M. I. A., Mahdy A. M. S., \& Farouk, R. M. (2010). Numerical solution of $12^{\text {th }}$ order boundary value problems by using homotopy perturbation method. Journal of Mathematics and Computer Science, 1(1), 14-27.

Siddiqi, S. S., \& Twizell, E. H. (1996). Spline solution of linear eighth-order boundary problems. Computer Methods in Applied Mechanics and Engineering, 131,309-325.

Siddiqi, S. S., Akram, G., \& Iftikhar, M. (2012). Solution of seventh order boundary problems by differential transform method. World Applied Sciences Journal, 16(11), 1521-1526

Tripathi, B. K. (2012). Solutions of fifth order boundary value problems. Mathematical Theory and Modeling, $9(2), 120-124$

Wazwaz, A. M. (2000). Approximate solutions to boundary value problems of higher order by the modified decomposition method. An International Journal of Computers and Mathematics with Applications, 40, 679-691

Wazwaz, A. M. (2001). The numerical solution of fifth order boundary value problems by the decomposition method. Journal of Computational and Applied Mathematics, 136, 259-270.

Wazwaz, A. M. (2001). The numerical solution of sixth-order boundary value problems by modified decomposition method. Appl. Math. Comput, 118, 311-325

Zhou, J. K. (1986). Differential transformation and its application for electrical circuits. Harjung University press, Wuuhan, China, (in Chinese).

\section{Copyrights}

Copyright for this article is retained by the author(s), with first publication rights granted to the journal.

This is an open-access article distributed under the terms and conditions of the Creative Commons Attribution license (http://creativecommons.org/licenses/by/3.0/). 